\title{
Separable evoked retinal and cortical potentials from each major visual pathway: preliminary results
}

\author{
T A BERNINGER, '2 G B ARDEN,' C R HOGG,' AND T FRUMKES 3 \\ From the 'Institute of Ophthalmology, Judd Street, London; ${ }^{2}$ University Eye Hospital, Mathildenstrasse 8 , \\ 8 Munich 2, FRG; and ${ }^{3}$ CUNY, Queen's College, New York, USA
}

SUMMARY Single cell experiments in primates show that there are two major parallel pathways named after the lamination in the lateral geniculate nucleus. Each of these systems can be preferentially excited by appropriate stimuli. Here we report that in man the polarity of the evoked potentials both in retina and in cortex depends on which of these pathways is stimulated. The identification of the resulting waveforms is thereby simplified-a matter of practical importance. The fact that at retina and cortex there are characteristic potentials may reflect the different cell biology of the two pathways.

Several parallel visual pathways run from the retina to the primary visual cortex and beyond. In the cat the distinction is based on the concept of a linear $(\mathrm{X})$ versus non-linear $(\mathrm{Y})$ response to light and to pattern. In the primate retina there is an additional complication, for about $90 \%$ of all retinal ganglion cells are colour coded and can be recognised on flatmounts as smaller 'beta' cells. They almost all project to the parvocellular layers of the lateral geniculate nucleus (LGN). The larger alpha cells project to the magnocellular layers.

Recordings from the LGN and the retina suggest that the larger ganglion cells respond poorly to coloured objects present on an equiluminant background of different colour but are sensitive to motion, flicker, and luminance spatial contrast. ${ }^{1-4}$ The smaller ganglion cells are better represented in the fovea, have smaller receptive fields, respond relatively poorly to achromatic flicker, and nearly all are colour coded, about $90 \%$ being of the red-green opponent type. ${ }^{.-12}$ This subdivision is preserved in the cerebrum. The two subsystems project to different layers of striate cortex, and cytochemical techniques show that subsequent information processing occurs in segregated portions of the visual cortex. ${ }^{1.1215}$ The colour coded cells are strictly linear. About $25 \%$ of the magnocellular layer cells (achromatic) are nonlinear.

Recently Kaplan and Shapley ${ }^{2}$ and Shapley and Perry $^{16}$ have proposed a scheme to explain the Correspondence to Professor G B Arden, Institute of Ophthalmology, Judd Street, London WC1H 9QS. differences and similarities between cat and primate visual systems. They propose that the primate equivalent of the cat $X$ and $Y$ system project to the magnocellular layers of the LGN. The additional colour coded, linear system, which is so prominent in the monkey and so sparse in the cat, projects exclusively to the parvocellular layers of the LGN.

The foregoing differentiation was established by single cell recordings in subhuman species ${ }^{1-18}$ and might be thought to have little bearing on clinical work or human experimentation, but psychophysical studies show that selective stimulation of the two pathways gives rise to differing sensations in the human subjects. ${ }^{19}$

We have investigated the possibility that there are electrophysiological correlates of these systems which can be recorded under clinical conditions.

The pattern electroretinogram (PERG) is recorded from the cornea. It should not be confused with the ERG evoked by flashes, which is produced by Müller cells in the outer retina. The PERG consists of two components, respectively cornea positive and negative $\left(\mathrm{P}_{50}\right.$ and $\left.\mathrm{N}_{95}\right),{ }^{20-22}$ both of which are generated in the inner retina. The former is partly developed by retinal ganglion cells, ${ }^{21-27}$ and the latter is associated with the activity of the optic nerve. ${ }^{212228}$ The PERG evoked by black-and-white patterns is partly pattern specific and partly evoked by local changes in luminance. When a chequerboard reverses, the increase in brightness of part of the screen is exactly matched by decreases in other parts. It follows that the average response of many different 
areas as seen in the PERG should be zero, if the response to increments of light was exactly equal and opposite to that for decrements. This is characteristic of a linear system. The fact that the PERG can be recorded is thus evidence of a non-linearity, which we know now has its cellular correlate in the $M_{y}$ cells. Although single cell recordings show that individual $P_{x}$ cells have a strictly linear organisation, the recordings of summed potentials might reveal some nonlinearities. Thus the effect of alternating isoluminant colours is of special interest. Furthermore there is little information about the effectiveness of motion in evoking a PERG.

The records from scalp electrodes, the visual evoked cortical potential (VECP), vary with the type of stimulus: triphasic waves, predominantly positive $\left(\mathrm{P}_{100}\right)$ are associated with pattern reversing stimuli and a complex sequence $\left(\mathrm{C}_{0}-\mathrm{C}_{3}\right)$ with the appearance of a monochromatic pattern..$^{29}$ The effective stimulus is not luminance but border contrast. The different waveforms associated with various patterns may be due to the fact that, as the pattern is altered, the cortical region generating the response also changes. Thus the large foveal projection into area 17 is at the posterior tip of the calcarine fissure, while the remainder of the visual field is represented by cortex buried in the fissure: the magnitude and even the polarity of the VECP evoked from peripheral retina might therefore be different to that from the fovea. The surface of the adjacent occipital cortex (area 18) has cells with differing properties. Another reason for the various types of evoked potential is that groups of cortical cells which respond selectively to motion may generate the responses to pattern reversal, which can be considered as the equivalent of two patterns moving in opposite directions. When coarse reversing patterns are viewed, the impression of motion is overwhelming, but for finer patterns the percept is quite different. Thus altering the size and reversal rate of a pattern can change the type of cortical element responding. Other distinctions can be made: for example cells responding preferentially to motion of large objects are likely to be found extrafoveally and in area 18 . Again the projection of the fovea is relatively deficient in blue-yellow sensitivity. ${ }^{30}$ Although it has been reported that colour-specific VECPs can be evoked, there is little information about the waveform, since early work used a technique (steady state recordings) which obscured waveform characteristics.

In the present report, we show that when PERG and VECP are tested with combinations of patterns in which appearance and reversal are combined with luminance contrast or isoluminance colour contrast. The waveforms and other properties of the evoked potentials change in ways which strongly suggest that the functional division of the visual system can also be demonstrated by these two non-invasive electrophysiological procedures.

Using equiluminous colour contrast stimuli simplifies the responses, a finding which is not only of practical interest. For these reasons we report our preliminary findings, since the complete analysis of cortical responses is a very complex matter.

\section{Material and methods}

The three authors and three other subjects provided the records described below. All had acuity corrected to at least $6 / 6$. Five had normal colour vision and one a mild red-green defect. PERGs and VECPs were recorded simultaneously with gold foil and $\mathrm{Ag} / \mathrm{AgCl}$ electrodes respectively. Gold foil electrodes were hooked in the lower fornix of the eye. The reference of the PERG was fixed to the ipsilateral temple. This electrode position reduces contamination of the PERG by remote cortical evoked potentials. ${ }^{3132}$ Each record was an average of more than 1000 and less than 1200 responses. $^{33.34}$ The electrical responses were amplified 100000 times, with a bandpass of $0 \cdot 3$ $100 \mathrm{~Hz}$. The stimuli were generated on a TV screen which subtended $22 \times 16^{\circ}$ and was placed $1.6 \mathrm{~m}$ from the subject's eye. The monitor used was of studio grade A quality (Electronic Visuals 5100 ), and was driven by a PLUTO colour graphics peripheral (IO Research Ltd). This has 8-bit digital to analogue converters for red, blue, and green channels. All pattern changes occurred during frame blanking periods. A trigger pulse was developed at pattern onset or at each reversal, and used to initiate an averaging procedure in a PDP 11/23 computer. The appropriate TV signals were calculated by a computer program. All colours were isoluminant (44 $\mathrm{cd} / \mathrm{m}^{2}$ ) and lay on protan or tritan colour confusion lines. Red-green or blue-yellow (RG or BY) patterns appeared from a uniform background in such a way that the average brightness and colour of the light emitted by the TV screen did not alter when the stimulus appeared (calibrated with a Minolta CS 1000 photometer: in addition we checked that neither the hue nor the luminance of a card illuminated by the TV-screen altered as the screen image changed). The CIE co-ordinates for red were $x=0 \cdot 347, y=0 \cdot 483$, for green $x=0.510, y=0.390$, for blue $x=0.302, y=0 \cdot 222$, and for yellow $x=0.443, y=0.445$. For the RG stimulus the background co-ordinates were $x=0.438$, $\mathrm{y}=0.428$ and for BY $\mathrm{x}=0.350, \mathrm{y}=0.301$. Patterns appeared for $200 \mathrm{~ms}$ and were replaced by a yellowish white or bluish white background for $600 \mathrm{~ms}$ or reversed abruptly every $400 \mathrm{~ms}$. Square wave gratings were used with a spatial frequency of 0.38 to $13 \cdot 2 \mathrm{c} /$ degree (for further details see Arden et al. ${ }^{3536}$ ). 


\section{Results}

The columns of Fig. 1 show responses recorded from the cornea, evoked either by the appearance of a pattern or by pattern reversal. The rows show various combinations of colour and luminance contrast. The appearance of a red-green coloured pattern should preferentially excite the smaller colour coded cells. It produced a small cornea negative response. Pattern reversal also evoked a negative response in the retina: the stimulus here would also be expected to excite preferentially colour coded cells.

The responses to blue-yellow stimuli were too small to be detected (less than the noise level, which is $=0.3 \mu \mathrm{V})$, probably because the proportion of retinal cells which respond to yellow-blue is only $5-10 \%$ of all colour coded cells.

The stimulus change from colour contrast to luminance contrast was achieved by moving the green grating through $180^{\circ}$ of phase and thus adding it to the red. The stimulus then became black-yellow

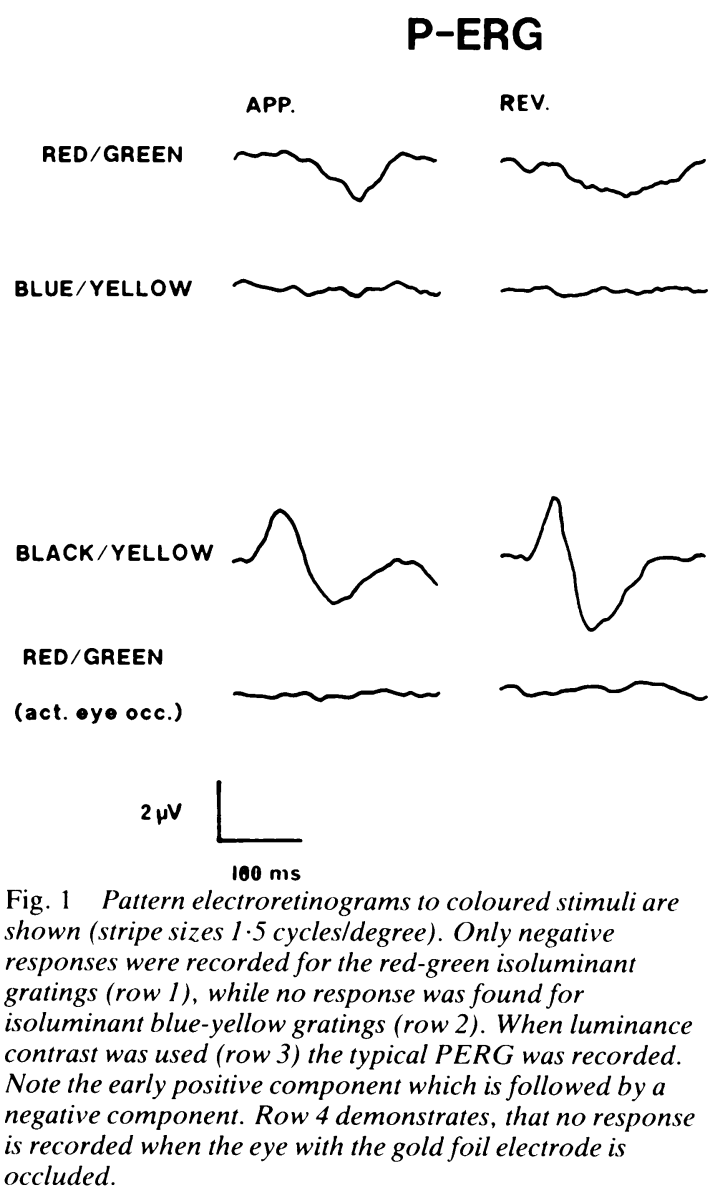

(row 3). Green-black or red-black patterns gave qualitatively the same results as black-yellow or black-white. The waveforms elicited in the retina were now quite different: biphasic positive-negative pattern ERGs were seen. In row 3 there is a local luminance change, but from the standpoint of an individual retinal neurone, with for example green cones feeding the receptive field centre, the change in the isoluminant red-green pattern will also represent a change in excitation: therefore the very large difference between the PERGs in rows 1 and 2, on the one hand, and row 3 on the other, requires explanation (see Discussion). Row 4 shows the responses obtained when the stimulus fell only on the fellow eye, while the eye with the gold foil electrode was occluded. No voltage changes were seen, showing that remote recording of the VECP (or the response of the fellow eye) was minimal.

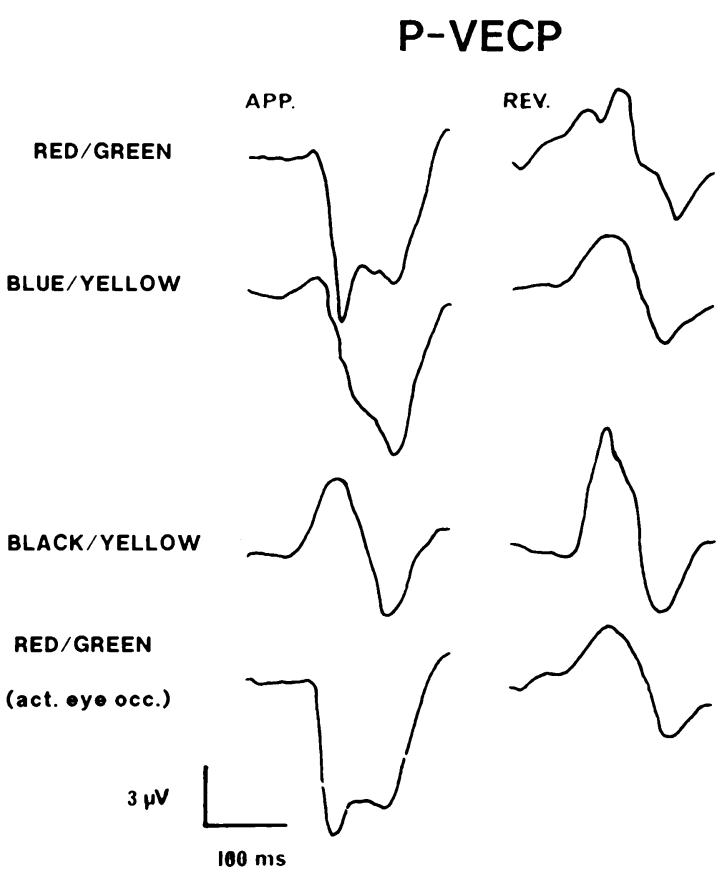

Fig. 2 Visual cortical evoked potentials under the same stimulus conditions as in Fig. 1. Surface positivity gives an upward deflection as shown. For isoluminant gratings a significant difference between appearance and reversal mode can be seen. For both red-green and blue-yellow gratings (rows 1 and 2) a large negative response is found, with an early maximum for red-green and a late maximum for blueyellow. Note that, unlike the PERG, reversal of a coloured pattern produces $a \mathrm{VECP}$ with an early positive component. Similar responses are also found for black-yellow stimuli (row 3). No significant change can be observed when the subject fixates the screen with one or the other eye (compare rows 1 and 4). 
Fig. 2 shows the VECPs associated with the same stimuli. The black-yellow reversal (row 3) represents the condition which is most familiar, a pattern formed by local changes in luminance. Note that for both appearance and reversal there was a surface positive response $\left(\mathrm{P}_{100)}\right)$ followed by a later negativity. The stimuli used were of relatively low spatial and temporal frequency. Such stimuli excite the illusion of motion, and it is considered that the accompanying VECP was produced by a motion and contrast detecting system. ${ }^{37}$ Motion is preferentially detected by the magnocellular system. Isoluminant red-green and blue-yellow gratings also produced large cortical responses, in contrast to the small voltages elicited in the retina (see Fig. 1). However, the effect of reversal and pattern appearance are quite different. The reversals under these experimental conditions evoked surface positive responses (like the luminance contrast patterns), but the appearance responses were of opposite polarity. The timing of the response to blue-yellow was delayed relatively to the red-green. Note that the first and fourth rows give very similar VECPs, since the cortical mechanisms can be excited from either eye.

Fig. 3 shows how the waveforms of the VECPs change with spatial frequency. For red-green patterns the appearance response was always negative, but the reversal response changed from positive to negative as the spatial frequency increased. The perceptal correlate of this change is that the higher spatial frequency gratings do not appear to 'drift' like the coarser ones. Reversing blue-yellow gratings gave surface positive waves. For higher spatial frequencies these responses were greatly attenuated. This is in part due to the effect of the longitudinal chromatic aberration of the human eye, which ${ }^{38}$ amounts to over $1.5 \mathrm{D}$ for the blue light emitted by the monitor. Consequently, the blue bars in a blue-yellow grating are defocused, and the contrast at 4 cycles/degree would be considerably reduced. The yellow bars are in focus, and therefore on the retina; the yellow-blue stimulus is reduced to a change in yellow luminance. It is difficult to calculate the exact change in luminance contrast caused by this

\section{COLOUR-VECP}

\section{RED/GREEN}

REVERSAL

BLUE/YELLOW

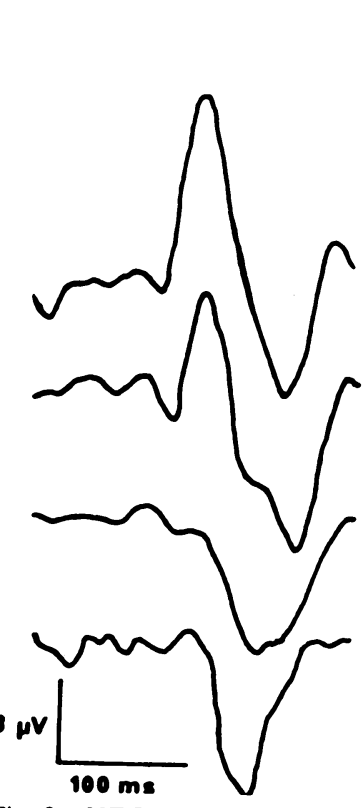

APPEAR

REVERSAL

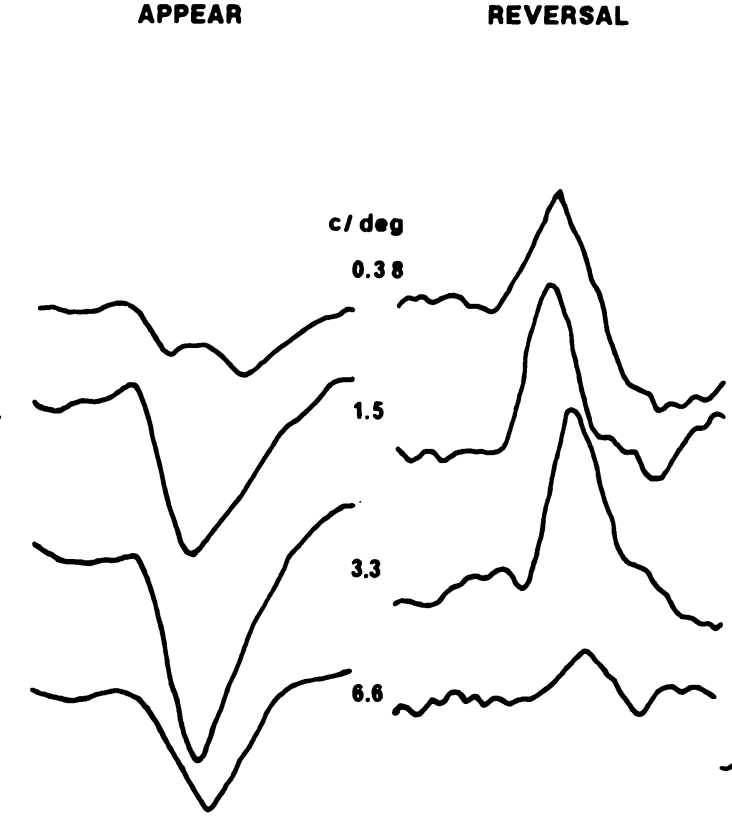

APPEAR

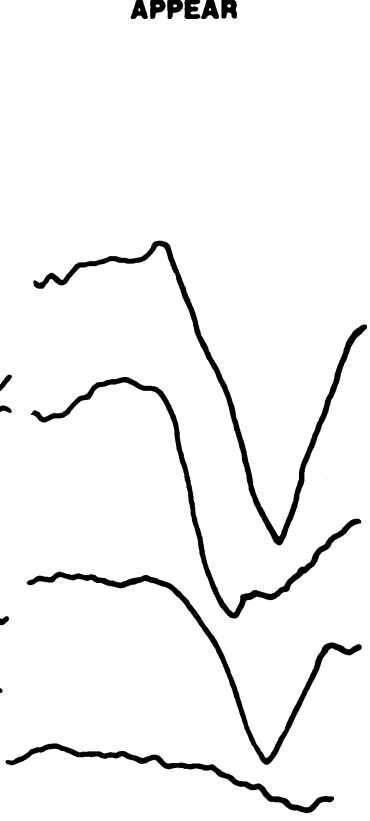

Fig. 3 VECP responses to isoluminant gratings of various stripe sizes are shown. Note the loss of the early positive component for higher spatial frequencies for the reversal mode (column 1). For red-green appearance (column 2) only negative response were recorded. The maximum amplitude occurs at $3 \cdot 3$ cycles/degree. By contrast for blue-yellow reversal (column 3) a positive component is found for all spatial frequencies. For pattern appearance (column 4) blue-yellow also shows a negative component which peaks at low spatial frequencies $(0 \cdot 38$ cycles/degree). 


\section{COLOUR-VECP}

RED/GREEN

MIDLINE

RIGHT

HEMISPHERE

\section{BLUE/YELLOW}

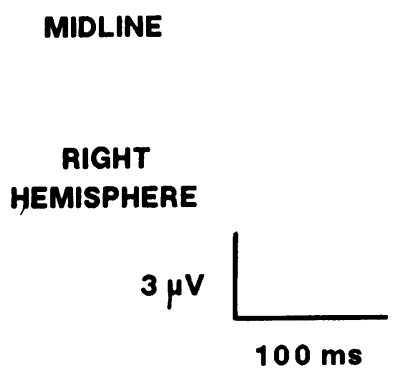

2 c/deg.
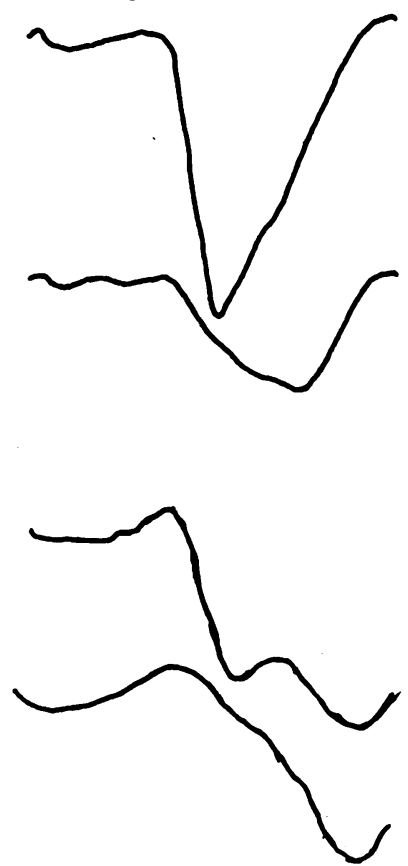

0.5 c/deg.
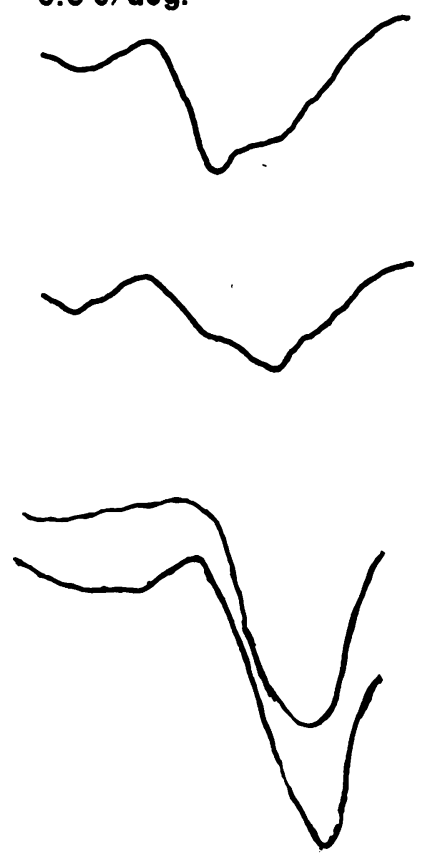

Fig. 4 Midline and right hemisphere responses for two spatial frequencies are shown. Note that for red-green the maximal response is found in the midline and for higher spatial frequency while for blue-yellow there is no significant amplitude difference between midline and periphery. (For this subject the response is even slightly larger in the hemisphere.) Further, the red-green response in the midline line peaks early at about $135 \mathrm{~ms}$. The maximum amplitude for the red-green response in the hemisphere peaks later (about $190 \mathrm{~ms}$ ). For blue-yellow the maximum response peaks significantly later, both in midline and hemisphere.

chromatic aberration. Campbell and Green's ${ }^{39}$ data on defocus suggest that a blue-yellow grating of $6 \mathrm{c} /$ degree would be demodulated by over $90 \%$. We could not obtain any definite appearance response with patterns of $>4 \mathrm{c} /$ degree, and this is consistent with the stimulus producing a colour-specific response.

Fig. 4 compares other aspects of the VECPs with colour appearance. Note that the red-green patterns always evoked a response which peaked at about $40 \mathrm{~ms}$. before the yellow-blue. Red-green patterns produced larger responses to higher spatial frequencies ( 2 c/degree) than did the blue yellow $(0.5 \mathrm{c} /$ degree). In addition, while the largest red-green response was obtained at the midline, $2 \mathrm{~cm}$ above the inion, the blue yellow response was as large, or larger on the hemisphere $5 \mathrm{~cm}$ lateral to the midline.

Fig. 5 shows the relative amplitude for red-green gratings from a subject with red-green deficiency compared with the average for three normal persons. The maximum amplitude of the response was normalised to 100 in each of the three normal persons and the red-green defective subject. (The responses -see figs. 3 and 4-have different components, and these are identified on the figures.) The lines indicate $+1 \mathrm{SD}$. The maximum response, at $135 \mathrm{~ms}$, occurs at the midline for all three normal persons.

The 25-year-old colour-defective has normal $6 / 6$ vision when wearing glasses. His colour vision deficiency was first established with Ishihara plates (he could not read number 3 ), and the colour contrast sensitivity measurements confirmed this. The threshold for red-green was $12 \%$, while the average normal value ranges from $3 \cdot 5-7 \cdot 5 \%$ with a mean of $5 \%$ (for details about this test see Arden et al. ${ }^{356}$ ). His maximal response was found to be the late component (N-195) (see below). At $135 \mathrm{~ms}$ the 


\section{COLOUR-VECP RED-GREEN}

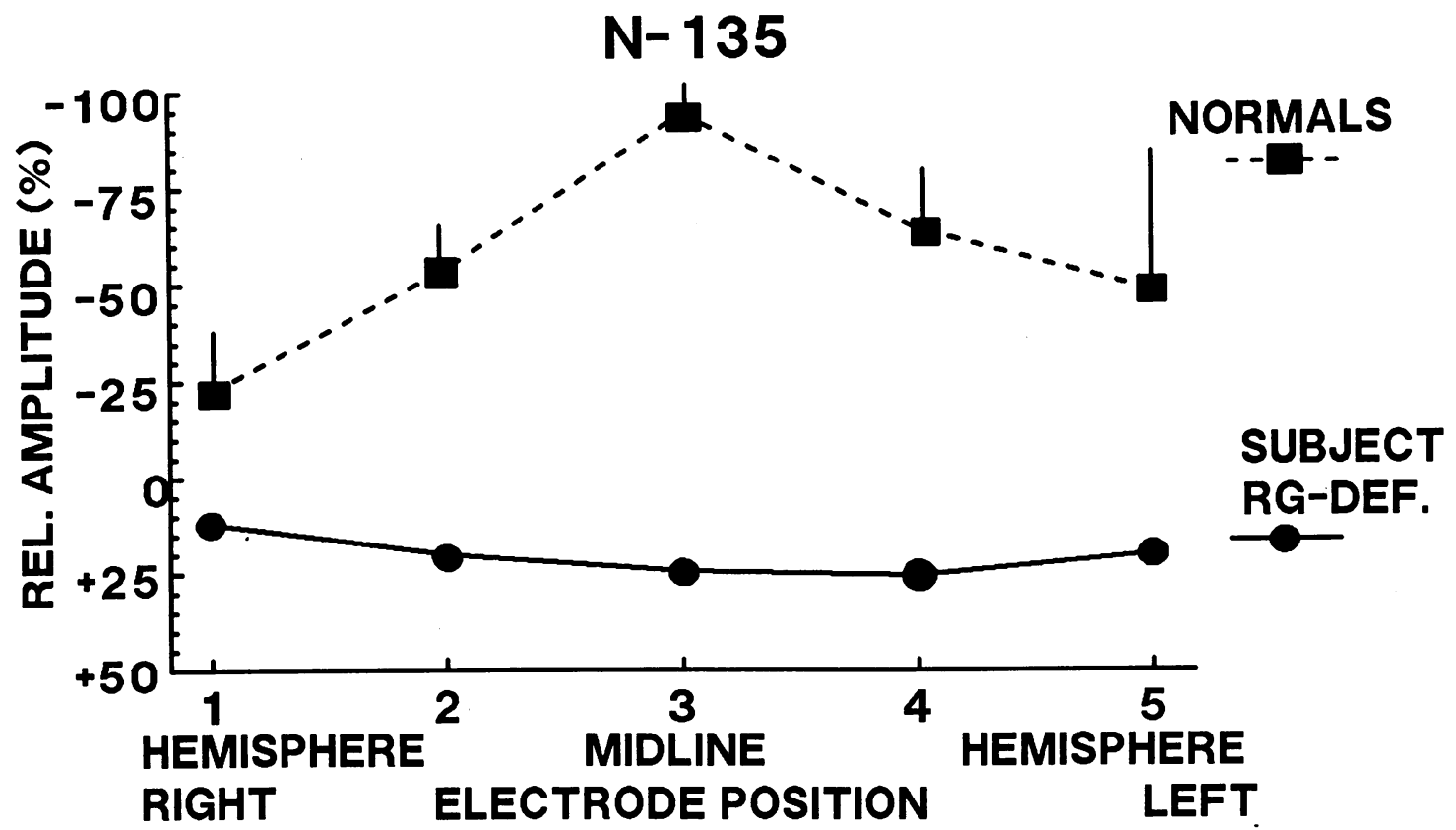

Fig. 5 Relative colour appearance VECP amplitudes of three normal persons (dotted line) and a subject with mild red-green defect (solid line). The maximal amplitude of the whole response was set to $100 \%$. for the normal persons the peak amplitude of the largest component was surface negative and occurred after about 135 ms after the pattern appearance of a grating with 3.3 cycles/degree. Note the larger amplitude at the midline electrode. By contrast for the same stimulus conditions the colour defective subject had a relatively small amplitude response which was of inverted polarity (surface positive). $R G$-def. $=$ red-green defective.

response was much smaller and the polarity was surface positive - that is, inverted with respect to the normal. There was no change in voltage with electrode position.

Fig. 6 shows the later N-195 responses for the subject and normal persons: negative polarity was found for both, but for the colour defective subject the responses were much larger. Note that, again, there is no sharp localisation of the response to the midline.

Fig. 7 compares the results from the same three normal persons and from the colour defective subject for blue-yellow gratings. The maximum response was found for all in the late component and for low spatial frequency. The result from the colour defective subject fell within the normal range.

\section{Discussion}

PATTERN ERGS TO COLOUR AND LUMINANCE When equiluminous colour contrast is used, the PERGs are very small and surface negative. Blue- yellow, in particular, produces no measurable response. In contrast the cortical responses are large: evidently there is some selective 'amplification'.

It is considered that colour coded cells in the retina ( $P$ cells, or beta ganglion cells) have linear characteristics - that is, they sum excitation and inhibition in a linear fashion. The proportions of ganglion cells with receptive field centres which respond to red and to green are roughly equal, and the proportion of cells which are excited by the increase of red light is nearly the same as the proportion excited by a decrease of red light (and the same is true for green). Colour coded cells have surrounds of opposing potentiality, but the balance between the two varies considerably in a random manner (the cells also lie at random positions with respect to the grating bars). It is evident that the net difference between excitation and inhibition caused by the change of the isoluminant coloured pattern should be nearly zero unless the cells had non-linear characteristics. Therefore it is not surprising that, although individual cells are greatly influenced by the 


\section{COLOUR-VECP \\ RED-GREEN}

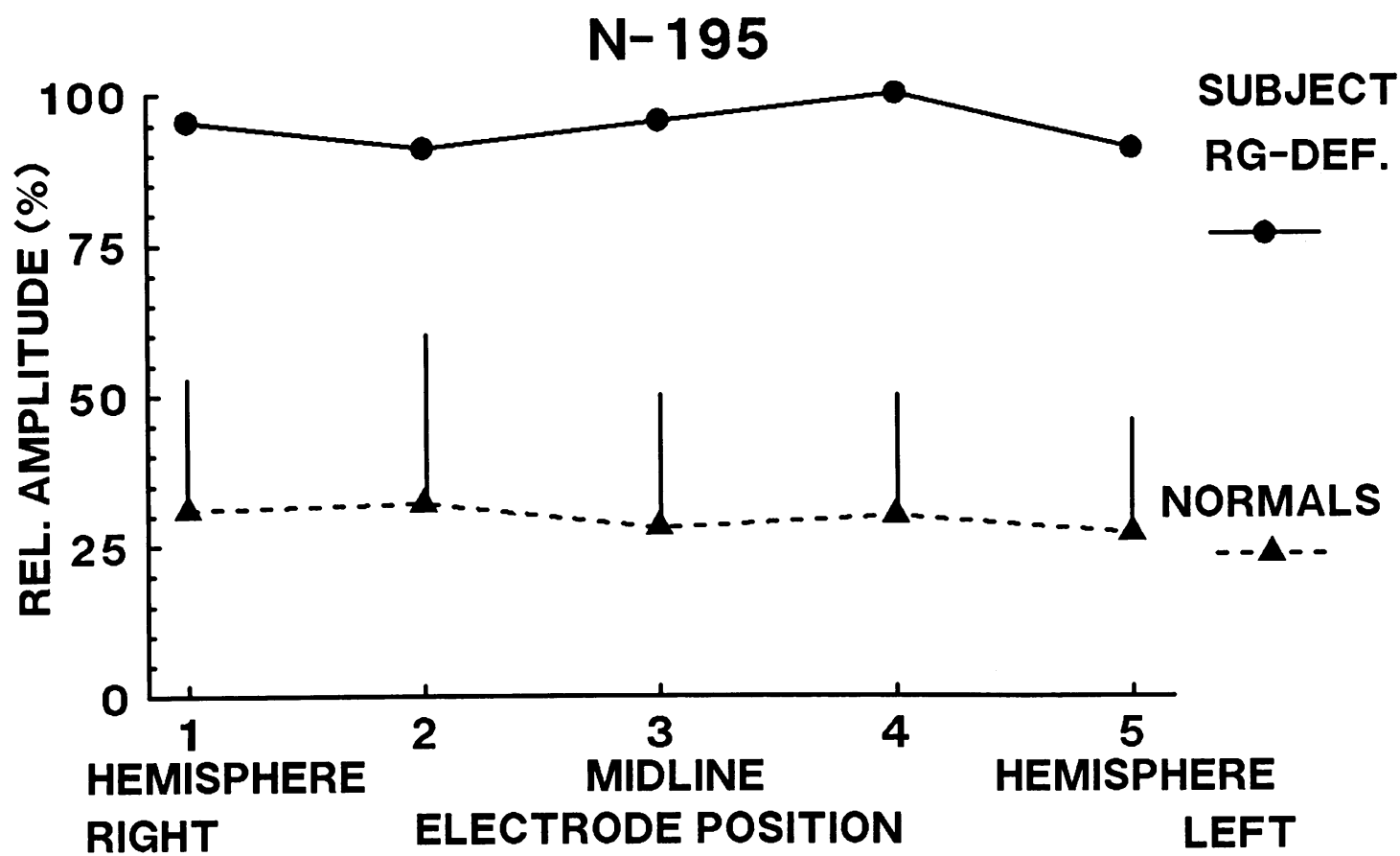

Fig. 6 Relative amplitudes for the late component $(N-195)$ of the VECP elicited by red-green appearance. For the colour defective subject this was the largest response. The amplitude was nearly constant at all electrode positions. The relative amplitude of the late component in the three normals is much smaller (dotted line).

stimulus, the PERG is very small, which implies that the average state of the assembly does not change. The small responses we can see may be due to small departures from isoluminance or to the fact that not all classes of colour coding are equally represented.

However, this poses a further question: what does respond to the yellow black grating? All the arguments deployed above apply with equal force to yellow-black stimuli: we would expect a small or absent PERG. This is obviously not the case. It might be thought that the colour contrast (red-green) was not as intense a stimulus as the luminance contrast (black-yellow). The effective contrast change for reversals is, however, twice that for appearance. But, for every combination of colour or luminance, appearance and reversal produce equal amplitude retinal responses. A qualitative method of analysing the difference is as follows: for a 'green centre' retinal ganglion cell the red phosphor can produce very little excitation or inhibition at the receptive field centre; therefore the contrast will appear to be nearly $100 \%$, as it is for black-yellow.
An alternative explanation which we favour is that yellow-black (like the black-and-white stimulus usually employed) stimulates a non-linearity in the responding retinal system, and indeed single cell recording has revealed a non-linearity $\left(\mathrm{M}_{\mathrm{y}}\right.$ cells $)$ in the magnocellular layer. Non-linearities have frequently been demonstrated for the PERG evoked by black-and-white patterns, but Arden and Vaegan ${ }^{34}$ failed to find non-linearities when using red-green patterns. If this is the explanation, then it follows that the positive portion of the PERG must be produced by a retinal system which includes such a nonlinearity - that is, by non-colour coded (alpha) cells.

Korth and Rix $^{40}$ have evoked pattern ERGs with very intense isoluminous red-green patterns $(22500$ td, that is, $3183 \mathrm{~cd} / \mathrm{m}^{2}$ for a pupil diameter of $3 \mathrm{~mm}$ or $1790 \mathrm{~cd} / \mathrm{m}^{2}$ for a pupil diameter of $4 \mathrm{~mm}$ in comparison with our mean luminance of $44 \mathrm{~cd} / \mathrm{m}^{2}$ ), and found the usual positive-negative waveforms. It seems likely that such intense stimuli could evoke activity in the achromatic channel as well as in the colour coded cells. Recently ${ }^{41}$ the same authors have used lower 


\section{COLOUR-VECP BLUE-YELLOW}
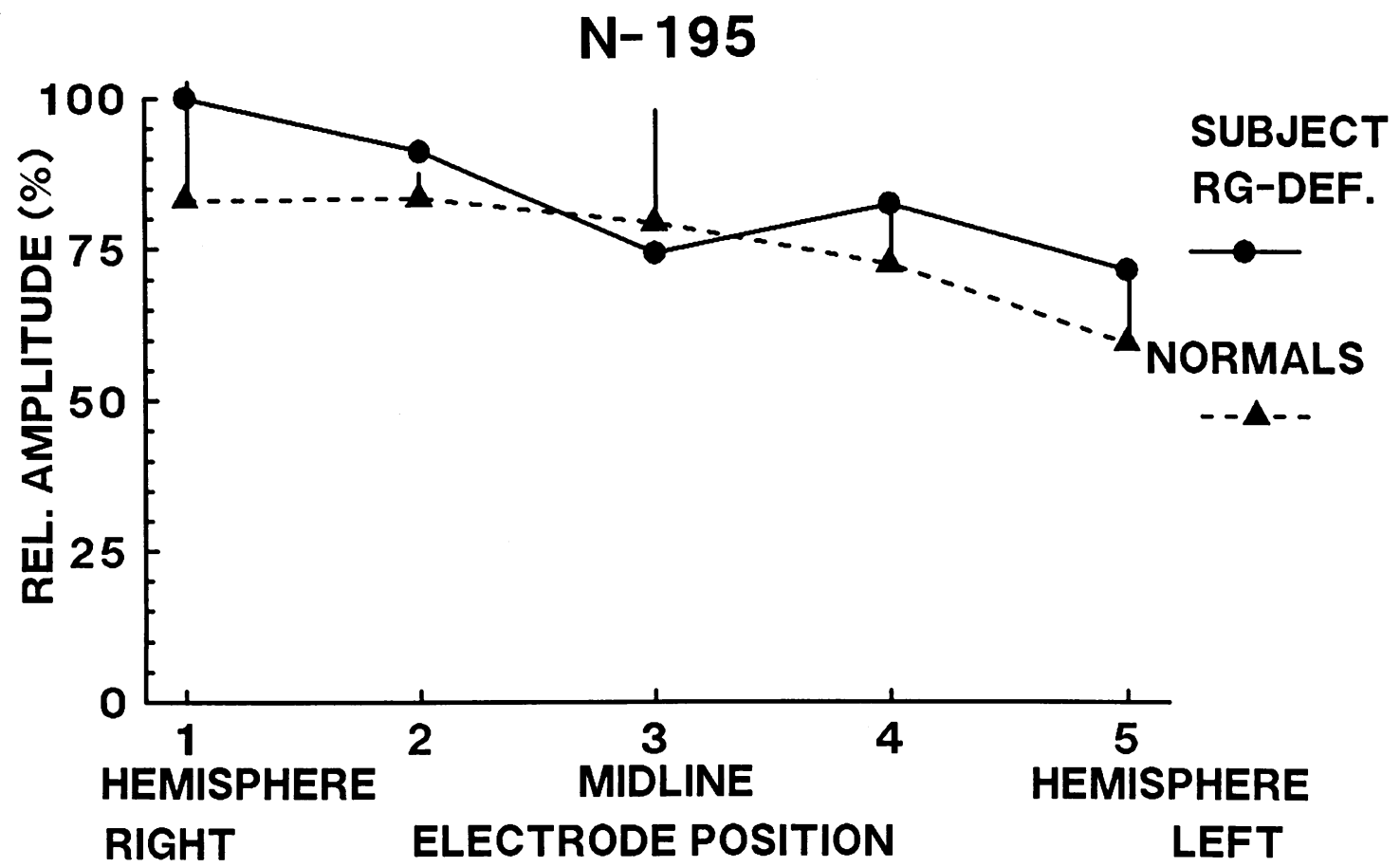

Fig. 7 Relative amplitude for blue-yellow colour appearance VEC Ps. Maximal responses were found for both normal persons and a red-green defective subject at a low spatial frequency $(0 \cdot 5$ cycle/degree). No influence of the electrode position on response amplitude can be observed, and both normal and defective persons gave similar results.

luminances, and with desaturated stimuli; their results are similar to those reported here.

\section{THE VECP TO APPEARANCE}

In the cortex VECPs evoked by isoluminant coloured gratings produce quite different responses to patterns in which there is luminance but no colour contrast. The VECP waveform and amplitude is somewhat variable from subject to subject, but the variations shown in Figs. 2, 3, and 4 are reproducible from subject to subject, and alteration of the stimulus causes predictable changes. In many circumstances isoluminant colours produce simple surface negative waves. Murray et al.$^{42}$ have shown similar results for red-green gratings and report that strict isoluminance is required for the negativity to be uncontaminated by positive components. Apparently the same is true for blue-yellow. In addition responses to blue yellow stimuli vanish for higher spatial frequencies at which blue modulation is diminished. Since only the fovea can resolve higher spatial frequencies, this may be an electrical demonstration of foveal tritanopia. ${ }^{30}$ Thus it appears that there are specific cortical responses to colour contrast patterns of low and mid range spatial frequency colour contrast. The responses to blueyellow and red-green are also easily distinguishable - by their timing and by the relative scalp location of the maximum voltage and their spatial tuning. It is interesting that there are perceptual differences in reaction time which correspond to the different peak times of the evoked potentials (EPs) ${ }^{43}$ Further work is required to determine whether these differences are due to gross differences in the cortical sites which generate the potentials.

THE VECP TO REVERSAL AND MOTION

When colour contrast gratings have low spatial frequency and are used in the pattern reversal mode, they produce the sensation of motion like monochromatic patterns, and the VECPs evoked resemble the VECPs produced by monochromatic patterns. It is known that the amplitude of such responses (to pattern reversal) varies with spatial frequency, but calculated spatial frequency for zero amplitude does 
not correspond to visual acuity. A much closer correlation is obtained with pattern appearance. Hence it is often suggested that the pattern reversal VECP evoked by coarse patterns is related to motion detection. This strongly suggests that the specific negative responses produced by the isoluminous coloured patterns, in appearance mode, may correspond to the operation of the parvocellular system. Consistent with this view is the finding that achromatic patterns (provided the spatial frequency is sufficiently high) may also evoke surface negative EPs. ${ }^{44}$

Thus all the observations indicate that the use of patterns containing colour or luminance contrast may distinguish between two parallel visual systems. This raises the further possibility that the structural organisation of parvo- and magnocellular pathways, or the different neurotransmitters, account for the polarity differences in the evoked potentials: in any case, the novel evoked potentials produced by colour may assist in understanding a variety of ophthalmological and neurological conditions.

\section{CLINICAL DATA}

Regan $^{46}$ as well as Murray et al. ${ }^{42}$ examined a deuteranopic patient with red-green gratings and did not record any response when the gratings were isoluminant. We examined a subject with mild redgreen deficiency and observed that the VECP response to red-green gratings had a completely different configuration when compared with that of normal persons, though blue-yellow gratings evoked normal responses. It is yet not possible to determine if there is a total loss of the $\mathrm{N}-135$ component in the colour-defective subject while the N-195 remain unchanged or whether there is a significant delay of the N-135.

It has been shown that hereditary colour vision defects can be detected by colour VECPs. Detection of acquired colour vision, however, is of more clinical importance. The ability of the colour VECP for this purpose has to be shown in future research.

T A Berninger has a research grant from the German Research Society (Be 1111/1-2). T E Frumkes and G B Arden acknowledge the assistance of grant 1RO1 EYO5 984-01A1 from the National Institute of Health. The authors gratefully acknowledge the assistance of the Special Trustees of Moorfields Eye Hospital.

\section{References}

1 Shapley RM, Kaplan E, Soodak R. Spatial summation and contrast sensitivity of $X$ and $Y$ cells in the lateral geniculate nucleus of the macaque. Nature 1981; 292: 543-5.

2 Kaplan E, Shapley RM. X and Y cells in the lateral geniculate nucleus of macaque monkeys. J Physiol (Lond) 1982; 330: 12543.

3 Kaplan E, Shapley RM. The primate retina contains two types of ganglion cells, with high and low contrast sensitivity. Proc Natl Acad Sci USA 1986; 83: 2755-7.
4 Derrington AM, Lennie P. Spatial and temporal contrast sensitivities of neurones in lateral geniculate nucleus of macaque. J Physiol (Lond) 1986; 59: 219-40.

5 Gouras PJ. Identification of cone mechanisms in monkey ganglion cells. J Physiol (Lond) 1968; 199: 533-47.

6 Gouras PJ. Antidromic responses of orthodromically identified ganglion cells in monkey retina. J Physiol (Lond) $1969 ; 204$ : 40719.

7 Gouras P, Krueger J. Responses of cells in foveal visual cortex of the monkey to pure color contrast. J Neurophysiol 1979; 42: 85060 .

8 Gouras P, Zrenner E. Enhancement of luminance flicker by color-opponent mechanism. Science 1979; 205: 587-9.

9 De Monasterio FM. Properties of concentrically organized X and Y ganglion cells of macaques retina. J Neurophysiol 1978; 41: $1394-417$.

10 De Monasterio FM. Center and surround mechanisms of opponent-color $\mathrm{X}$ and $\mathrm{Y}$ ganglion cells of the retina of macaques. J Neurophysiol 1978; 41: 1418-34.

11 De Monasterio FM. Properties of ganglion cells with atypical receptive-field organization in retina of macaques. $J$ Neurophysiol 1978; 41: 1435-49.

12 Blakemore C, Vital-Durand F. Distribution of X-and Y-cells in the monkey's lateral geniculate nucleus. J Physiol (Lond) 1981; 320: $17-8$.

13 Livingstone MS, Hubel DH. Anatomy and physiology of a color system in the primate visual cortex. J Neurosci 1984; 4: 309-56.

14 Livingstone MS, Hubel DH. Connections between layer 4B of area 17 and the thick cytochrome oxidase stripes of area 18 in the squirrel monkey. $J$ Neurosci 1987; 7: 3371-7.

15 Hubel DH, Livingstone MS. Segregation of form, and stereopsis in primate area 18 . $J$ Neurosci $1987 ; 11: 3378-415$.

16 Shapley R, Perry VH. Cat and monkey retinal ganglion cells and their visual funtional roles. TINS 1986; 9: 229-35.

17 Wiesel TN, Hubel DH. Spatial and chromatic interactions in the lateral geniculate body of the rhesus monkey. $J$ Neurophysiol 1966; 29: 1115-56.

18 Hubel DH, Wiesel TN. Ferrier lecture. Functional architecture of macaque monkey visual cortex. Proc R Soc Biol 1977; 198: 971-6.

19 Livingstone MS, Hubel DJ. Psychophysical evidence for separate channels for the perception of form, color, movement, and depth. J Neurosci 1987; 7: 3416-68.

20 Berninger TA, Schuurmans RP. Spatial tuning of the pattern ERG across temporal frequency. Doc Ophthalmol 1985; 61: 1725.

21 Holder GE. Significance of abnormal pattern electroretinography in anterior pathway dysfunction. Br J Ophthalmol 1987; 71: 166-71.

22 Ryan S, Arden GB. Electrophysiological discrimination between retinal and optic nerve disorders. Doc Ophthalmol 1988; 68: 247-55.

23 Maffei L, Fiorentini A. Electroretinographic responses to alternating gratings before and after section of the optic nerve. Science 1981; 211: 953-5.

24 Maffei L, Fiorentini A, Bisti S, Hollander H. Pattern ERG in the monkey after section of the optic nerve. Exp Brain Res 1985; 59: 423-5.

25 Groneberg A, Teping C. Topodiagnostik von Sehstörungen durch Ableitung retinaler und kortikaler Antworten auf Umkehr-Kontrastmuster. Ber Dtsch Ophthalmol Ges 1980; 77: 409-17.

26 Dawson WW, Maida T, Rubin M. Human pattern evoked retinal responses are altered by optic atrophy. Invest Ophthalmol Vis Sci 1982; 22: 796-803.

27 Hollander H, Bisti S, Maffei L, Hebel R. Electroretinographic responses and retrograde changes of retinal morphology after intracranial optic nerve section: a quantitative analysis in the cat. Exp Brain Res 1985; 55: 483-93. 
28 Ohta H, Tamura T, Kawasaki K, Yonemura D. negative wave in human pattern ERG and its suppression in glaucoma. Nippon Ganka Gakkei Zasshi 1986; 90: 882-6.

29 Jeffreys DA. The physiological significance of pattern visual evoked potentials. In: Desmedt JE, ed. Visual evoked potentials in man. Oxford: OUP, 1977: 134-67.

30 Williams DR, MacLeod IA, Hayhoe MM. Foveal tritanopia. Vision Res 1981: 21: 1341-75.

31 Hess RF, Baker CL. Human pattern-evoked electroretinogram. J Neurophysiol 1984; 51: 939-51.

32 Berninger TA. The pattern electroretinogram and its contamination. Cin Vision Sci 1986; 1: 185-90.

33 Arden GB, Vaegan, Hogg CR. Clinical and experimental evidence that the pattern electroretinogram (PERG) is generated in more proximal retinal layers than the focal electroretinogram (FERG). Ann NY Acad Sci 1982; 388: 580-601.

34 Arden GB, Vaegan. Electroretinograms evoked in man by local uniform and pattern stimulation. J Physiol (Lond) 1983; 341: 85104.

35 Arden GB, Gündüz K, Perry S. Colour vision testing with a computergraphics system: preliminary results. Doc Ophthalmo 1988; 69: 167-74.

36 Arden GB, Gunduz K, Perry S. Colour vision testing with a computergraphics system. Clin Vis Sci 1988; 2: 303-20.

37 Kulikowski J. Human averaged occipital potentials evoked by pattern and movement. J Physiol (Lond) 1974; 242: 70-1.
38 Wyszeki G, Stiles WS. Color Science. 2nd ed. New York: Wiley, 1984.

39 Campbell FW, Green DG. Optical and retinal factors affecting visual acuity. J Physiol (Lond) 1965: 181: 576-93.

40 Korth M, Rix R. The pattern ERG in response to coloured stimuli. Vision Res 1988; 28: 41-7.

41 Korth M, Rix R. Electrical responses of the human eye to changes in saturation of the stimulating light. Doc Ophthalmol 1988; 69: 131-7.

42 Murray IJ, Parry NRA, Carden D, Kulikowski JJ. Human visual evoked potentials to chromatic and achromatic gratings. Clin Vis Sci 1987; 1: 231-44.

43 Cole BC, McDonald WA. Defective colour vision can impede information acquisition from reductantly color coded video displays. Ophthalmic Physiol Opt 1988; 8: 198-206.

44 Drasdo N. Cortical potentials evoked by pattern presentation in the foveal region. In: Barber C, ed. Evoked potentials. Baltimore: University Park Press, 1969.

45 Plant GT, Zimmern RL, Durden K. Transient visually evoked potentials and onset of sinusoidal gratings. Electroencephalogr Clin Neurophysiol 1983; 56: 47-58.

46 Regan D. Evoked potentials specific to spatial patterns of luminance and colour. Vision Res 1973; 13: 2381-402.

Accepted for publication 20 October 1988. 